\title{
Resin Tags have no Contribution on Push-out Bond Strength of Self- Adhesive Resin Cement
}

\section{Crivano $\mathrm{E}^{1}$, Reis $\mathrm{KR}^{2 *}$, Reis $\mathbf{C}^{3}$ and De-Deus $\mathbf{G}^{4}$}

${ }^{1}$ Department of Prosthodontics, Veiga de Almeida University, Rio de Janeiro, Rio de Janeiro, Brazil

${ }^{2}$ Department of Prosthodontics and Dental Materials, Federal University of Rio de Janeiro, School of Dentistry, Rio de Janeiro, Rio de Janeiro, Brazil

${ }^{3}$ Department of Dental Clinic, Espírito Santo Federal University, Vitória, Espírito Santo, Brazil

${ }^{4}$ School of Dentistry, Grande Rio University (UNIGRANRIO), Duque de Caxias, Rio de Janeiro, Brazil

\begin{abstract}
Aim: To assess the contribution of resin tags in the interfacial bond strength of self-adhesive cement used to lute fiber posts into root canals.

Methodology: Twenty extracted human canine teeth were selected and root filled. Roots were randomly assigned into two groups $(n=10)$ according to pre-treatment of root dentin: non-etched (G1) or etched using $37 \%$ phosphoric acid (G2). Glass fiber posts (White Post) were luted into the root canals using the self-adhesive cement Rely $X^{\mathrm{TM}}$ UniChem. Before insertion of the post, the cement was labeled with Rhodamine B isothiocyanate. Roots were sectioned transversally into slices of $1.5 \mathrm{~mm}$ thickness to perform the tests at the coronal, middle and apical regions of the root canal. Each slice was analyzed using confocal laser scanning microscopy to determine the presence or absence of resin tags, and then, subjected to a push-out test. Bond strengths data (MPa) were analyzed by Student t-test $(\alpha=0.05)$.
\end{abstract}

Results: The qualitative analysis of the post-dentin interface revealed that was not possible to observe the formation of resin tags into the root dentin in $\mathrm{G} 1$, whereas all slices belonging to $\mathrm{G} 2$ exhibited the presence of resin tags. For the push-out test, there were no significant differences between G1 $(10.5 \pm 3.53)$ and G2 $(10.61 \pm 3.84)$ groups $(p<0.05)$ in all root canal regions.

Conclusions: Resin tags, as a result of root dentin etching, did not affect the push-out bond strength of fiber posts to root canals when using the self-adhesive cement Rely $X^{\top M}$ Uni Cem.

Keywords: Confocal laser scanning microscopy; Root dentin; Resin cement; Smear layer

\section{Introduction}

The achievement of an effective adhesion to the dentin tissue is a real challenge task mainly due to its specific microstructural features and inherent moisture [1,2]. Moreover, the scenario became still more challenger within the spatial geometry of the root canal. In a noteworthy review, Schwartz highlighted the critical conditions for an optimal intra-radicular bonding [3]. Concerning these challenges and limits, alternative bonding strategies, as well as the development of new adhesive cement generations have been frequently introduced with the purpose of producing a reliable bonding to the root dentin tissue.

Some years ago, a new class of resin cement was developed and introduced to the dental market and it was so-called as self-adhesive universal resin cement (Rely X UniCem, 3M ESPE Dental Products, St. Paul, MN, USA). Rely X UniCem combines adhesive and cement in one single application. The manufacturer states that the cement is a paste/paste, fluoride-releasing and radiopaque dual-cured resin cement that is formulated for luting crowns, bridges, inlays, onlays and posts. In addition, the fact that it is thought to bond to dentin without the requirement of any kind of dentin conditioning or pre-treatment is a point that must be considered $[4,5]$. In this way, the interesting features related to the self-adhesive resin cement support the large body of scientific investigation around this material over the last years.

Traditional adhesive systems have dentin-hybridization process as the base to achieve an effective adhesion. On the other hand, selfadhesive universal resin cement relies on the properties of phosphoric acid methacrilate acid-esther monomers [6,7] to produce adhesion by a direct chemical reaction between dentin hydroxyapatite and fluoroaluminosillicate glass fillers-a property that had already been proved in glass-ionomer cements $[8,9]$. According to De Munck et al. [6],
Rely $\mathrm{X}^{\mathrm{TM}}$ UniCem reacts to dentin surface, but a real hybrid layer and resin tags are not produced. As a point of fact, dentin hybridization is a collagen-depended approach where the presence of resin tags inside the dentine tubules occurs as a natural consequence of the interplay between chemical nature of the adhesive and smear layer removal. Pashley et al. [10], using a theoretical modeling study, concluded that the dentin bond strength, created by etch-and-rinse adhesives, is a sum of the strengths of resin tags, hybrid layer and surface adhesion. Nevertheless, the contribution of the resin tags to the bond strength is controversial and this subject has been the target of previous studies $[11,12]$. To our knowledge, there is no peer-reviewed study on the influence of resin tags on the bond strength of the RelyX $\mathrm{X}^{\mathrm{TM}}$ UniCem self-adhesive resin cement. Therefore, the objective of the present study was to assess the potential correlation between the presence of resin tags and the intracanal final bond strength created by Rely $\mathrm{X}^{\mathrm{TM}}$ UniCem selfadhesive resin cement on fiber post cementation. Based on the main purpose of the study, two null-hypotheses were formulated and tested:

(1) The resin tags are observed in etched and non-etched root dentin;

*Corresponding author: Kátia Rodrigues Reis, Rua Prof. Rodolpho Paulo Rocco $325 / 2^{\circ}$ andar, Ilha da Cidade Universitária, Rio de Janeiro, RJ, Brazil 21941-590, Tel: +55 21 2562-2024; E-mail: katiarreis@hotmail.com

Received February 10, 2014; Accepted February 19, 2014; Published February 21,2014

Citation: Crivano E, Reis KR, Reis C, De-Deus G (2014) Resin Tags have no Contribution on Push-out Bond Strength of Self-Adhesive Resin Cement. Dentistry 4: 216. doi: $10.4172 / 2161-1122.1000216$

Copyright: $\odot 2014$ Crivano E, et al. This is an open-access article distributed under the terms of the Creative Commons Attribution License, which permits unrestricted use, distribution, and reproduction in any medium, provided the original author and source are credited. 
(2) There is no significant difference in the bond strength achieved in etched or non-etched root dentin.

\section{Methods}

\section{Sample size calculation}

The ideal sample size for the study was determined using a correlation bivariate normal model (Exact family, $\mathrm{G}^{*}$ Power 3.1 for Macintosh). The following values were used: $r_{2}=0.5, \alpha=0.05, \beta=0.85$ and correlation $\mathrm{P}$ for $\mathrm{H}_{0}=0$. The results indicated a minimum sample size of 8 teeth and a critical $r$ of 0.375 as the upper limit for accepting $\mathrm{H}_{0}$.

\section{Sample selection and specimen preparation}

This study was revised and approved by the Ethics Committee, Nucleus of Collective Health Studies, Veiga de Almeida University, Rio de Janeiro, Brazil. A sample of 20 extracted human maxillary canines, being $20 \pm 1 \mathrm{~mm}$ in length with straight roots and complete apices, was selected after patient's informed consent.

\section{Endodontic procedures}

Standard access cavities were made and the working length established by placing a size $15 \mathrm{~K}$-file (Dentsply/Maillefer, Ballaigues, Switzerland) through the apical foramen into the canal until visible at the apical foramen and subtracting $1 \mathrm{~mm}$. The coronal and middle third of each canal was prepared using Gates Glidden drills (Dentsply/ Maillefer) sizes $6,5,4,3$, and 2 at $1 \mathrm{~mm}$ increments creating a 0.02 $\mathrm{mm} \cdot \mathrm{mm}^{-1}$ taper [13]. The apical third was prepared with FLEXOFILES (Dentsply, Maillefer) sizes 60, 55, 50, and 45 in a balanced force technique [14].

The canals were irrigated between each file with $0.5 \mathrm{~mL}$ of freshly prepared $5.25 \% \mathrm{NaOCl}$ using a disposable syringe and 27 -gauge needle. In order to remove the smear layer, $3 \mathrm{~mL}$ of $17 \%$ EDTA was used for 3 minutes as a final rinse. The canals were dried with paper points (Dentsply-Maillefer).

The prepared teeth were filled by the same operator using the single cone technique and Grossman sealer. A size 40 file was used to pick up a measured amount of sealer $(20 \mu \mathrm{L})$ which was determined by the employment of fixed-volume semi-automatic micropipette. The sealer was placed into the canal while rotating the tooth counterclockwise. A size 550.02 taper gutta-percha cone (Diadent, Chongchong Buk Do, Korea) was placed in the canal up to the full working length. The filled roots were stored for 7 days in physiological saline solution at $37^{\circ} \mathrm{C}$.

\section{Post preparation procedures}

The coronal-middle gutta-percha fillings were removed of all teeth with a size 2 Gates Glidden drill until a depth of $14 \mathrm{~mm}$. The WHITE POST SYSTEM (FGM Produtos Odontológicos Ltd., Joinville, Santa Catarina, Brazil) was elected for the present study and the post \#3 size was selected. In this way, the root canal space was enlarged with a number 3 low-speed, pre-shaping drill (White Post, FGM Produtos Odontológicos) leaving a $6 \mathrm{~mm}$ long apical seal. The depth of the post space preparation was $14 \mathrm{~mm}$. A final rinse with $10 \mathrm{ml}$ saline solution was used to remove debris.

Prior to posts cementation, the teeth were randomly assigned into two groups, using a computer algorithm (http://www.random.org). In G1, no acid etching was performed in root canal (non-etched, control group). In G2, the post space was etched with $35 \%$ phosphoric acid gel (VOCO - Cuxhaven, Germany) for $15 \mathrm{~s}$ and rinsed thoroughly (etched group).

\section{Post cementation procedures}

The root canal post spaces were dried lightly with paper points. Each post was cleaned with ethanol and air-dried. One dose of RELYX ${ }^{\mathrm{TM}}$ UNICEM was dispensed on a glass plate, mixed and labeled with $0.1 \%$ Rhodamine B isothiocyanate to enable the fluorescence mode under confocal laser scanning microscopy (CLSM) [15-17]. A lentulo bur (Maillefer) was used with a conventional engine of low rotation of $500 \mathrm{rpm}$ to pick up a measured amount of sealer $(30 \mu \mathrm{L})$ into the post space. WHITE POST number \#3 (FGM Produtos Odontológicos) was inserted through the root canal until achieving the total post space length. The resin cement was allowed to set by light-curing through the post for 40 seconds with the tip of the LED positioned at the top of the fiber post. The output intensity $\left(1000 \mathrm{~mW} / \mathrm{cm}^{2}\right)$ was constantly measured during the experiment with the aid of a Demetron light radiometer (DENTSPLY, De Trey, Konstanz). After post cementation, specimens were stored in a humidity atmosphere at $37^{\circ} \mathrm{C}$ for $48 \mathrm{~h}$.

\section{Confocal laser scanning microscopy}

After that, each specimen was transversally sectioned at 6, 8, 10 and $12 \mathrm{~mm}$ from the apex using a low-speed saw (Isomet, Buhler, Ltd. Lake Bluff, NY, USA) with a diamond disc (diam. $125 \mathrm{~mm} \times 0,35 \mathrm{~mm} \times 12,7$ $\mathrm{mm}$ - model $33^{\circ} \mathrm{C}$ ), with continuous water irrigation to prevent overheating. In this manner, 3 slices of $1.4 \pm 0.2 \mathrm{~mm}$ per root were created, resulting in 36 slices/group. The thickness of each slice was confirmed with a digital caliper to an accuracy of $0.001 \mathrm{~mm}$ (Avenger Products, North Plains, OR) [18].

A metallographic preparation was performed only on the coronallyfacing surface of each slice [19]. Then, these surfaces were examined under CLSM (Carl Zeiss, Jena, Germany) and images were recorded using the fluorescent mode (laser wavelengths of $568 \mathrm{~nm}$ ) with the maximum resolution of about $220 \mathrm{~nm}$ laterally and $330 \mathrm{~nm}$ axially. In this way, nondestructive images were obtained from subsurface regions down to about $20.5 \mu \mathrm{m}$. One photomicrography of the full root dentine perimeter was taken for each slice to provide the analyses of intracanal resin tags.

\section{Micro push-out assessment}

The sectioned roots were then stored in a humidity atmosphere at $37^{\circ} \mathrm{C}$ for $24 \mathrm{~h}$ for rehydration and the micro push-out test was made. The fine-tune parallelism was ensured by a laser beam device, and the root filling of each sample was loaded with a 0.5 -mm-diameter cylindrical plunger. The plunger tip was sized and positioned to touch only the root filling. The load was always applied in an apical-coronal direction to avoid any constriction interference as a result of root canal taper during push-out testing. Loading was performed on a universal testing machine (EMIC DL200MF, São José dos Pinhais, PR, Brazil) at a speed of $0.5 \mathrm{~mm} / \mathrm{min}$ until debonding occurred. A load $x$ time curve was plotted during the test by using a real-time software [18]. The area of the bonded interface was calculated using the formula, $A=2 \pi r \times h$, considering $r=0.75 \mathrm{~mm}$ (root canal space radius) and $h=$ slice thickness (high). To express the bond strength in Megapascals, the load at failure, recorded in Newtons, was divided by the area of the bonded interface [20].

\section{Data presentation and statistical analysis}

An operator, blinded, to which samples were matched to each group, analyzed the resin tags on a dichotomy mode: present or absent. The analyses were repeated twice to ensure reproducibility.

A Student t-test for intragroup comparisons assigned the "group/ 
Citation: Crivano E, Reis KR, Reis C, De-Deus G (2014) Resin Tags have no Contribution on Push-out Bond Strength of Self-Adhesive Resin Cement. Dentistry 4: 216. doi:10.4172/2161-1122.1000216

root canal portion" interaction of bond strength data. Then, the analysis of the raw pooled data revealed a bell-shaped distribution (D'Agostino \& Person omnibus normality test). Further, statistical analysis was performed by using parametric tests to compare the two groups. Due to the same response to the mechanical test, Student t-test was also used for statistics. The alpha-type error was set at 0.05. Prisma 5.0 (GraphPad Software Inc., La Jolla, CA, USA) and Origin 6.0 (Microcal Software, Inc, Northampton, MA) were used as analytical tools.

\section{Results}

\section{Interfacial analysis}

In general, CLSM analysis of the post-dentin interface revealed a quite regular pattern of resin tags distribution between the two tested groups. In G1 resin tags free interfaces were always found in the samples of non-etched control group (Figures 1 and 2).

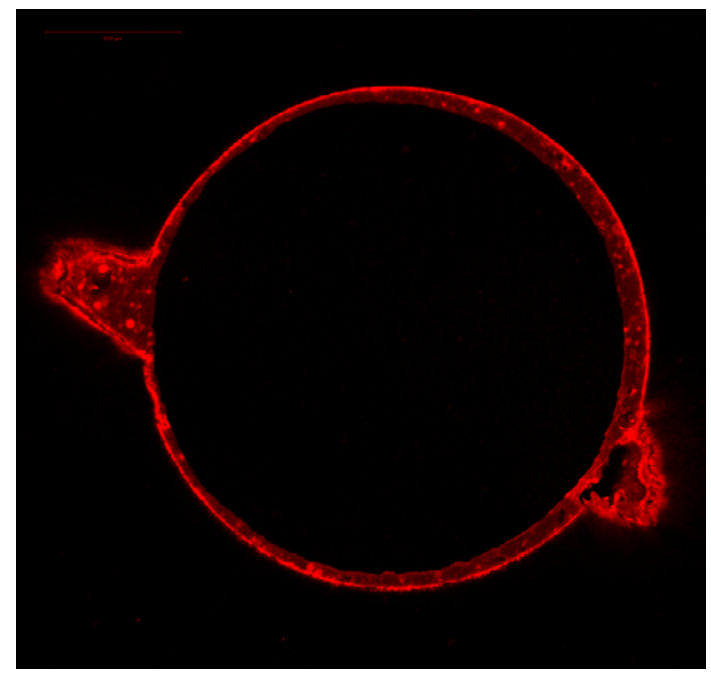

Figure 1: Box-plots of the push-out bond strength (MPa). Similar letters indicate no significant statistical differences between groups; $P<.05$.

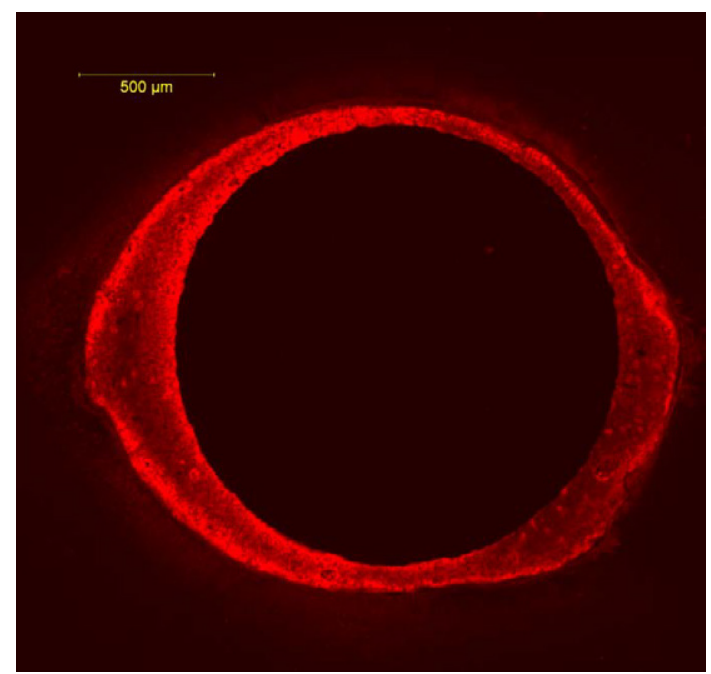

Figure 2: A representative subsurface confocal image of a resin tag-free region of a specimen from $\mathrm{G} 1$ group displaying the absence of tubular penetration of the cement into the root dentin.

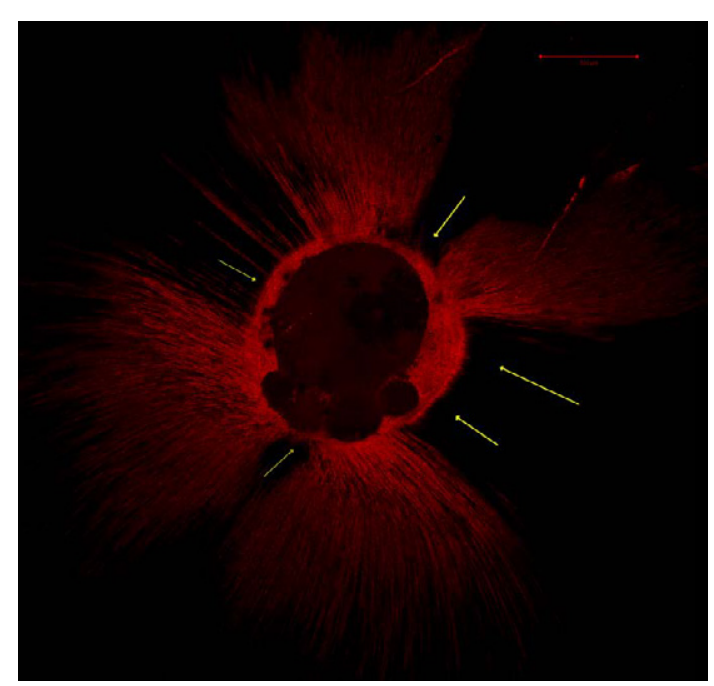

Figure 3: Subsurface confocal image of a resin tag-free region of a specimen from G1 group; the absence of tubular penetration of the cement into the root dentin is clearly observed.

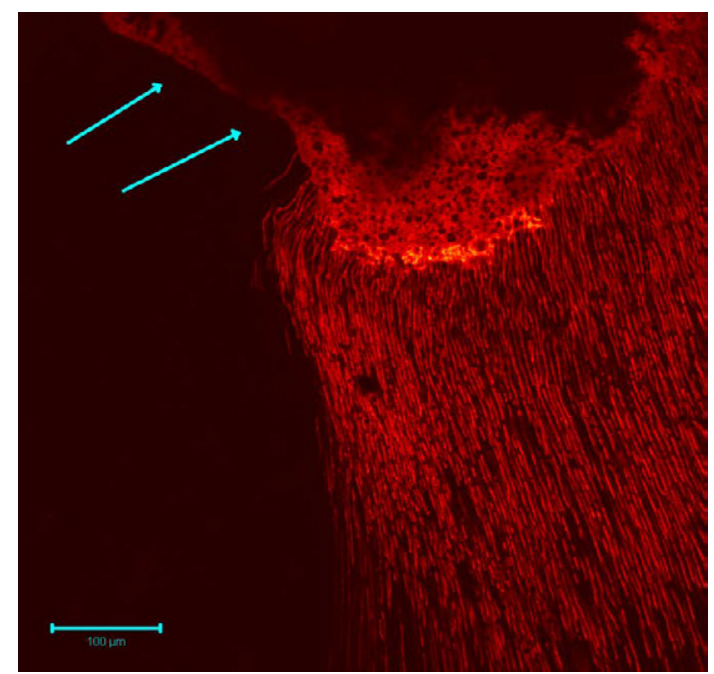

Figure 4: Subsurface confocal image of a resin tag-contain region of a specimen from G2 group revealing the abundant tubular penetration of the cement into the root dentin. Resin tag-free regions (arrows) are also observed in less quantity.

On the other hand, in G2, which root dentin was etched with 35\% phosphoric acid gel, all samples showed resin tags formation into the root dentin (Figures 3-6)

\section{Micro push-out assessment}

The result of the interaction analysis 'group/root region' was not significant $(\mathrm{P}>0.05)$. This allowed the pool of the data obtained at different root regions to perform a single statistical analysis by group. In other words, the variable 'root region' was excluded from the statistical analysis. Thus, it was possible to calculate only a single mean and a standard deviation, from all 36 slices, per each group.

In general, all samples, without exception, revealed a minimal measurable bond strength that could be detected by the present experimental design. Figure 7 presents the results in Box-whisker plots. In, G1 the bond strength mean value was $10.5 \pm 3.53 \mathrm{MPa}$, being 7.5 


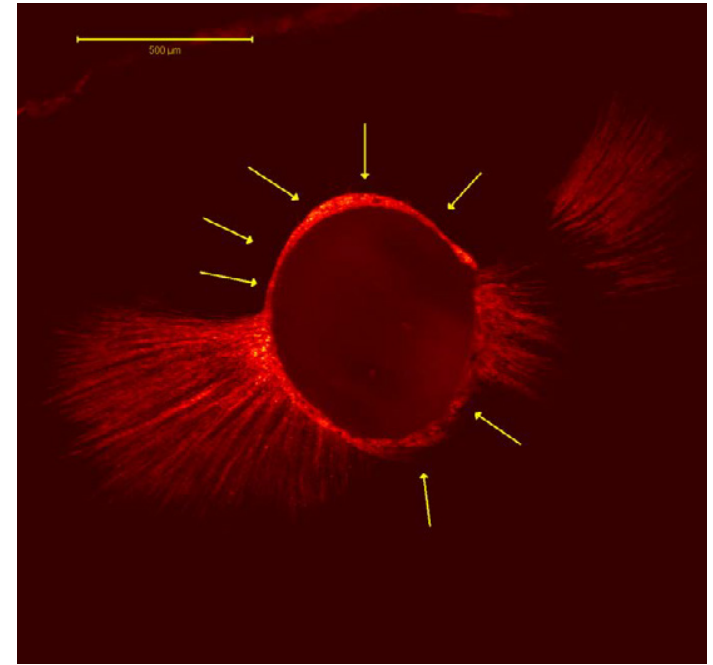

Figure 5: A close-up subsurface confocal image displaying a region with vast formation of long resin tags and a region with absence of resin tags into the root dentin (arrows) of a specimen from G2 group.

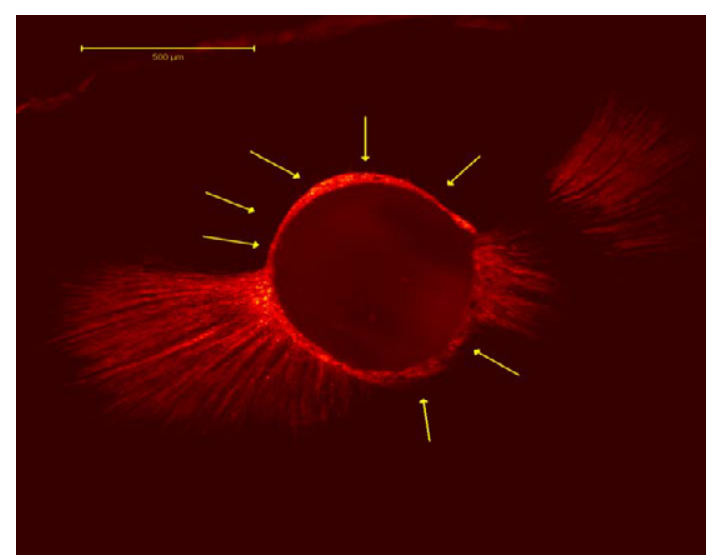

Figure 6: Subsurface confocal image of a specimen from G2 group displaying the abundant presence of resin tags into the root dentin. The arrows display regions where there was no formation of resin tags.

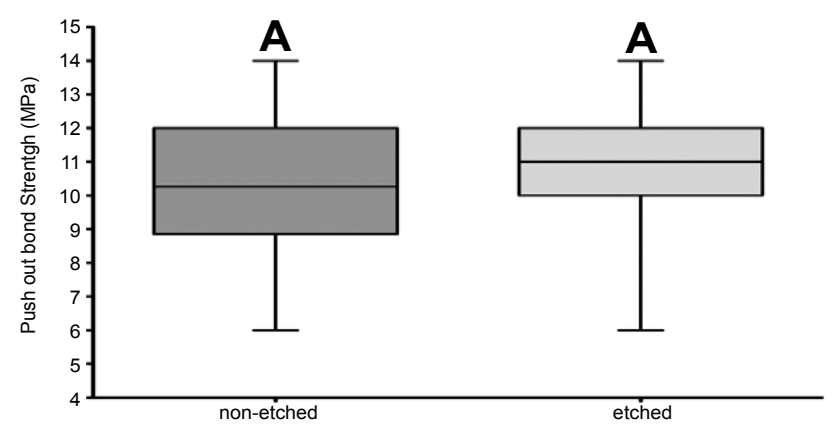

Figure 7: Subsurface confocal image of a specimen from G2 group displaying the abundant presence of resin tags into the root dentin around all the perimeter of the root canal.

the minimum and 15.2 the maximum values. In $\mathrm{G} 2$, the mean value was $10.61 \pm 3.84 \mathrm{MPa}$, being 7.2 the minimum and 13.6 the maximum values. The Student $t$-test did not show any differences between the two tested groups $(\mathrm{P}<0.05)$ (Figure 7).

\section{Discussion}

As a consequence of the CLSM interfacial analysis, the first null hypothesis of the present study was completely rejected. In general, the two tested groups demonstrated different interfacial patterns, clearly revealed by the images (Figures 1-6). The G1-control group-the use of non-etched specimens followed the manufacturer's instructions and revealed a complete absence of resin tags into the dentine tubules. The opposite effect was found on all samples of G2 experimental group. Thus, it is clear that the Rely $\mathrm{X}^{\mathrm{TM}}$ UniCem self-adhesive universal resin cement is able to penetrate deeply into the root dentin tubules when intracanal surface is etched with $37 \%$ phosphoric acid gel.

Nevertheless, the second null hypothesis formulated in the present study was fully accepted, because there were no significant differences in bond strength between the control and the experimental groups. Thus, it was impossible to determine a significant correlation between resin tags formation and intracanal adhesion quality when RelyX ${ }^{\mathrm{TM}}$ UniCem self-adhesive universal resin cement was used. Therefore, it suggests that the adhesion mechanism of this material is not dependent upon the dentin hybridization as well as the formation of resin tags. This finding corroborates with the results of previous studies that also described a superficial morphological interaction with the dentin substrate after the use of this cement when the manufacturer's instructions were followed [15,21]. A chemical adhesion between dentin hydroxiapatite and fluoro-aluminosillicate glass fillers had been reported and it demonstrated a similar pattern to the glass ionomer cements (3M ESPE RelyX ${ }^{\mathrm{TM}}$ UniCem product file).

The present results underscore the lack of effectiveness of dentin pre-treatment with $37 \%$ phosphoric acid for the use of RelyX $\mathrm{X}^{\mathrm{TM}}$ UniCem self-adhesive resin cement. This finding is relevant for a twofold reason: (1) It stresses the efficacy of the adhesion mechanism of the self-adhesive resin cement; (2) It elucidates that the manufacturer's recommendations are correct, since the absence of penetration of the self-adhesive cement into the root dentine tubules or even the presence of the smear layer on intracanal dentin did not influence the overall adhesion quality.

The good performance of the RelyX $\mathrm{X}^{\mathrm{TM}}$ UniCem self-adhesive resin cement for fiber post cementation may also be attributed to the clinical use simplicity, in comparison to conventional resin cements. Indeed, the technical sensitivity of resin cements is claimed to be decreased, since the advent of the self-adhesive resin cements allowed the elimination of the critical clinical steps of acid etching, primering and adhesion [5].

The results of the present study are also in accordance with previous studies that used the same experimental model to assess the intracanal adhesion quality obtained with RelyX ${ }^{\mathrm{TM}}$ UniCem [5,21-26]. The similarity of the data states the reproducibility of the push-out test and restates itself as the main experimental model to determinate the intracanal adhesion quality.

The introduction of CLSM, associated to the use of fluorescent labels was responsible for a significant improvement on the analysis of the adhesive interface and adjacent structures, such as hybrid layer and resin tags.

Previous studies have already used CLSM to investigate the quality of endodontic fillings [27] and the penetration of sealers into the root dentin tissues [28]. However, the present investigation followed a methodology focused on dentin adhesion-an approach that revealed to be more adequate for the analysis of the quality of interfacial integrity [29]. 
Some advantages related to the use of CLSM may also be taken into consideration, especially in comparison to the high vacuum scanning electron microscopy (SEM) the most traditional image method used to analyze the dentin tissues and root filling materials. CLSM almost does not produce any type of technical artefact, because samples are observed in environmental conditions of temperature, pressure and humidity. Moreover, CLSM does not require sample metallization, neither special vacuum conditions to obtain the images [30]. The use of epoxy resin replicas is also unnecessary, because the absence of special vacuum conditions avoid the creation of false gaps. In addition, it is important to emphasize the non-destructive character of the CLSM, which allows the superposition of two distinctive experimental models by using the same specimens.

Another positive aspect related to CLSM refers to its ability to generate an analysis in deep (under-superficial observation). In the experimental conditions of the present study, 25 images were obtained on regular vertical gaps of $0.86 \mu \mathrm{m}$ - allowing observations up to $\sim 20,53 \mu \mathrm{m}$ in deep. This depth is dependent of several factors, such as: the nature and translucence of the sample, the quality of surface preparation and the type of lenses used. Therefore, it is possible to verify if the interfacial gap is deep or shallow, or even if it is solely an artefact created during the observation and capture of the image. Future studies that use this resource may take volumetric measurements of the interfacial gaps areas (tridimensional measurements), which, without a doubt, will be more interesting than the bidimensional images.

Several tests are available for the evaluation of intracanal adhesion quality. The push-out test is one of them. In fact, it determines the intracanal post retention, which reflects the pattern of adhesion quality achieved between post and root dentin. Push-out tests are well adjusted model for this purpose [20] and this may justify the large body of investigations using this experimental model.

When the micro-tensile test is employed for intracanal bond strength evaluation, a high sample loss value occurs during specimen's preparation. It is a result of premature failures probably due to the low bond strength values achieved into the root canals, compromising the results obtained using this methodology [31].

One of the disadvantages of the push-out test was attributed to the creation of non-uniform forces at the adhesive interface [32]. However, the use of thinner slices (approximately $1.5 \mathrm{~mm}$ ), such as those used in the present study, might eliminates this disadvantage [20]. In the present study, as root possesses a total length of $12 \mathrm{~mm}$, more than three slices by specimen could be used in the push-out test, which also contributed to balance some distortion derived from the generation of non-uniform forces in the adhesive interfaces.

A clear advantage of the push-out test is that this experiment generates statistically normally-distributed data, which means that data distribution is close to a Gaussian curve [18]. This characteristic may be taken into consideration as an advance face to other experimental models usually employed in dental researches, because it reflects more reliable data. Additionally, it is worth to point out that generate wellbehaved data from biological samples is a difficult and uncommon task in dental research.

In conclusion, the dentin pre-treatment with $37 \%$ phosphoric acid gel and the subsequent formation of resin tags did not influence the quality of intracanal adhesion obtained with the self-adhesive resin cement RelyX ${ }^{\mathrm{TM}}$ UniCem.

\section{Acknowledgements}

The authors deny any conflicts of interest.

\section{References}

1. Frankenberger R, Kramer N, Petschelt A (1999) Fatigue behaviour of different dentin adhesives. Clin Oral Investig 3: 11-17.

2. Tay FR, Gwinnett JA, Wei SH (1998) Micromorphological spectrum of acidconditioned dentin following the application of a water-based adhesive. Dent Mater 14: 329-338.

3. Schwartz RS (2006) Adhesive dentistry and endodontics. Part 2: bonding in the root canal system-the promise and the problems: a review. J Endod 32 $1125-1134$.

4. Radovic I, Mazzitelli C, Chieffi N, Ferrari M (2008) Evaluation of the adhesion of fiber posts cemented using different adhesive approaches. Eur J Oral Sci 116: 557-563.

5. Radovic I, Monticelli F, Goracci C, Vulicevic ZR, Ferrari M (2008) Self-adhesive resin cements: a literature review. J Adhes Dent 10: 251-258.

6. De Munck J, Vargas M, Van Landuyt K, Hikita K, Lambrechts P, et al. (2004) Bonding of an auto-adhesive luting material to enamel and dentin. Dent Mater 20: $963-971$

7. Gerth HU, Dammaschke T, Zuchner H, Schafer E (2006) Chemical analysis and bonding reaction of RelyX Unicem and Bifix composites--a comparative study. Dent Mater 22: 934-941.

8. Wilson AD, Prosser HJ, Powis DM (1983) Mechanism of adhesion of polyelectrolyte cements to hydroxyapatite. J Dent Res 62: 590-592.

9. Yoshida Y, Van Meerbeek B, Nakayama Y, Snauwaert J, Hellemans L, et al. (2000) Evidence of chemical bonding at biomaterial-hard tissue interfaces. J Dent Res 79: 709-714.

10. Pashley DH, Ciucchi B, Sano H, Carvalho RM, Russell CM (1995) Bond strength versus dentine structure: a modelling approach. Arch Oral Biol 40 1109-1118.

11. Lohbauer U, Nikolaenko SA, Petschelt A, Frankenberger R (2008) Resin tags do not contribute to dentin adhesion in self-etching adhesives. J Adhes Dent 10: 97-103.

12. Stona P, Borges GA, Montes MA, Júnior LH, Weber JB, et al. (2013) Effect of polyacrylic acid on the interface and bond strength of self-adhesive resin cements to dentin. J Adhes Dent 15: 221-227.

13. Shemesh H, Wu MK, Wesselink PR (2006) Leakage along apical root fillings with and without smear layer using two different leakage models: a two-month longitudinal ex vivo study. Int Endod J 39: 968-976.

14. Roane JB, Sabala CL, Duncanson MG Jr (1985) The "balanced force" concept for instrumentation of curved canals. J Endod 11:203-211.

15. Bitter K, Paris S, Martus P, Schartner R, Kielbassa AM (2004) A Confocal Lase Scanning Microscope investigation of different dental adhesives bonded to roo canal dentine. Int Endod J 37: 840-848.

16. Ordinola-Zapata R, Bramante CM, Bernardineli N, Graeff MS, Garcia RB, et al. (2009) A preliminary study of the percentage of sealer penetration in roots obturated with the Thermafil and RealSeal-1 obturation techniques in mesial root canals of mandibular molars. Oral Surg Oral Med Oral Pathol Oral Radio Endod 108: 961-968.

17. Ordinola-Zapata R, Bramante CM, Graeff MS, del Carpio Perochena A, Vivan RR, et al. (2009) Depth and percentage of penetration of endodontic sealers into dentinal tubules after root canal obturation using a lateral compaction technique: a confocal laser scanning microscopy study. Oral Surg Oral Med Oral Pathol Oral Radiol Endod 108: 450-457.

18. De-Deus G, Namen F, Galan J Jr, Zehnder M (2008) Soft chelating irrigation protocol optimizes bonding quality of Resilon/Epiphany root fillings. J Endod 34: 703-705.

19. De-Deus G, Paciornik S, Pinho Mauricio MH, Prioli R (2006) Real-time atomic force microscopy of root dentine during demineralization when subjected to chelating agents Int Endod J 39: 683-692.

20. Goracci C, Tavares AU, Fabianelli A, Monticelli F, Raffaelli O, et al. (2004) The adhesion between fiber posts and root canal walls: comparison between microtensile and push-out bond strength measurements. Eur J Oral Sci 112: 353-361. 
Citation: Crivano E, Reis KR, Reis C, De-Deus G (2014) Resin Tags have no Contribution on Push-out Bond Strength of Self-Adhesive Resin Cement. Dentistry 4: 216. doi:10.4172/2161-1122.1000216

21. Bitter K, Paris S, Pfuertner C, Neumann K, Kielbassa AM (2009) Morphological and bond strength evaluation of different resin cements to root dentin. Eur $J$ Oral Sci 117: 326-333.

22. Goracci C, Sadek FT, Fabianelli A, Tay FR, Ferrari M (2005) Evaluation of the adhesion of fiber posts to intraradicular dentin. Oper Dent 30: 627-635.

23. Wang VJ, Chen YM, Yip KH, Smales RJ, Meng QF, et al. (2008) Effect of two fiber post types and two luting cement systems on regional post retention using the push-out test. Dent Mater 24: 372-377.

24. Kececi AD, Ureyen Kaya B, Adanir N (2008) Micro push-out bond strengths of four fiber-reinforced composite post systems and 2 luting materials. Oral Surg Oral Med Oral Pathol Oral Radiol Endod 105: 121-128.

25. Giachetti L, Grandini S, Calamai P, Fantini G, Scaminaci Russo D (2009) Translucent fiber post cementation using light- and dual-curing adhesive techniques and a self-adhesive material: push-out test. J Dent 37: 638-642.

26. Mazzoni A, Marchesi G, Cadenaro M, Mazzotti G, Di Lenarda R, et al. (2009) Push-out stress for fibre posts luted using different adhesive strategies. Eur $\mathrm{J}$ Oral Sci 117: 447-453.
27. Gharib SR, Tordik PA, Imamura GM, Baginski TA, Goodell GG (2007) A confocal laser scanning microscope investigation of the epiphany obturation system. J Endod 33: 957-961.

28. Patel YG, Nehal KS, Aranda I, Li Y, Halpern AC, et al. (2007) Confocal reflectance mosaicing of basal cell carcinomas in Mohs surgical skin excisions. J Biomed Opt 12: 034027.

29. Bonfante G, Kaizer OB, Pegoraro LF, do Valle AL (2007) Tensile bond strength of glass fiber posts luted with different cements. Braz Oral Res 21: 159-164.

30. Tay FR, Sano H, Carvalho R, Pashley EL, Pashley DH (2000) An ultrastructural study of the influence of acidity of self-etching primers and smear layer thickness on bonding to intact dentin. J Adhes Dent 2: 83-98.

31. Bouillaguet S, Troesch S, Wataha JC, Krejci I, Meyer JM, et al. (2003) Microtensile bond strength between adhesive cements and root canal dentin Dent Mater 19: 199-205

32. Sudsangiam S, van Noort R (1999) Do dentin bond strength tests serve a useful purpose? J Adhes Dent 1: 57-67. 